\title{
APLIKASI PENGENALAN SENJATA TRADISIONAL INDONESIA MENGGUNAKAN AUGMENTED REALITY BERBASIS ANDROID
}

\author{
Ayu Lutfi Novitasari \\ Program Studi Teknik Informatika S1, Fakultas Teknologi Industri \\ Institut Teknologi Nasional Malang, Jalan Raya Karanglo km 2 Malang, Indonesia \\ ayulutfinovitasari@gmail.com
}

\begin{abstract}
ABSTRAK
Indonesia memiliki beragam kebudayaan salah satunya adalah senjata tradisional. Kebudayaan merupakan jati diri suatu bangsa yang harus dilestarikan. Salah satunya dengan menjadikan sejarah kebudayaan sebagai salah satu materi pembelajaran di sekolah. Namun dengan media terbatas dan cara mengajar yang monoton meyebabkan siswa tidak maksimal dalam menyerap ilmu pengetahuan. Saat ini kita membutuhkan metode yang dapat menunjang minat belajar siswa sekaligus untuk melestarikan kebudayaan Indonesia.

Augmented Reality adalah teknologi yang dapat menggabungkan dunia maya dan nyata yang diproyeksikan menggunakan ala elektronik secara real time. Dengan memanfaatkan teknologi AR untuk membuat aplikasi pengenalan senjata tradisional Indonesia menggunakan metode marker based tracking. Marker sendiri adalah image target untuk mengenali objek dan informasi.

Hasil penilitian ini berupa aplikasi pengenalan senjata tradisional Indonesia. Dengan tujuan sebagai media untuk meningkatkan minat belajar pelajar dan masyarakat umum serta untuk melestarikan kebudayaan khususnya senjata tradisional Indonesia. Aplikasi berbasis Android dengan pilihan 2 bahasa yaitu Indonesia dan Inggris. Aplikasi juga dilengkapi dengan guide book yang berisi deskripsi masing-masing senjata tradisional, peta letak geografis, dan marker. Marker yang terdeteksi akan menampilkan objek senjata tradisional masing-masng daerah dilengkapi dengan informasi dalam bentuk audio.
\end{abstract}

Kata kunci : senjata tradisional Indonesia, Augmented Reality, Android

\section{PENDAHULUAN}

Indonesia memiliki beragam kebudayaan yang perlu dilestarikan. Salah satunya dengan menjadikan kebudayaan sebagai salah satu materi pembelajaran di sekolah. Namun, media yang terbatas dan cara mengajar yang monoton menyebabkan pelajar tidak maksimal dalam memahami materi. Selain menggunakan metode konvensional buku, menggunakan teknologi computer sebagai penunjang kegiatan belajar mengajar merupakan alternatif. Pratama menyebutan salah satu metode yang digunakan adalah konsep belajar elektronik (elearning). Yaitu suatu metode pembelajaran yang memanfaatkan teknologi computer dan multimedia yang digabungkan sehingga menjadi aplikasi edukasi interaktif.[1]

Informasi yang didapatkan kebanyakan bersumber pada buku manual dan e-book saja. Maka dibutuhkan metode yang lebih efektif, salah satunya adalah memanfaatkan augmented reality sebagai metode pembelajaran. Augmented Reality adalah teknologi yang dapat menggabungkan dunia maya dan nyata secara real time dan diproyeksikan menggunakan elektronik. Dengan menggunakan metode marker based tracking. Marker berfungsi sebagai penanda suatu informasi.

Dengan aplikasi pengenalan senjata tradisional Indonesia selain dapat meningkatkan minat belajar siswa tentang kebudayaan, tetapi juga memberikan gambaran bentuk asli senjata layaknya seperti alat peraga. Diharapkan aplikasi dapat digunakan sebagai media pembelajaran dan pelestarian kebudayaan bangsa khususnya senjata tradisional Indonesia.

Hasil dari penelitian ini berupa aplikasi pengenalan senjata tradisional Indonesia berbasis Android. Aplikasi menggunakan 2 bahasa yaitu Bahasa Indonesia dan Bahasa Inggris. Aplikasi juga dilengkapi dengan informasi berupa audio. Pada guide book terdapat keterangan berupa cara penggunaan, peta geografis, deskripsi singkat senjata, dan marker. Untuk proses scan marker agar mendapatkan hasil yang baik, disarankan dilakukan pada siang hari baik di dalam maupun di luar ruangan.

\section{TINJAUAN PUSTAKA}

\subsection{Penelitian Terdahulu}

Walesa Danto, Dkk pada tahun 2011 melakukan penelitian pada papernya dengan judul Analisis Metode Occlusion Based pada Augmented Reality dengan Studi Kasus: Interaksi dengan Objek Virtual Secara Real Time Menggunakan Marker. Dalam papernya penulis memaparkan bahwa pada penelitian ini memanfaatkan data berupa objek catur 2D. Selain itu system koordinat dan tracking marker sangat berpengaruh dalam melakukan interaksi antara objek virtual dengan mengguanakan 
tangan secara real time pada system augmented reality. Berdasarkan penelitian tersebut didapatkan hasil bahwa metode occlusion based dapat menjadi salah satu alternatif cara interaksi antara objek 2D dengan benda nyata secara real time. Dengan waktu respon yang cukup baik yaitu 25 fps. Namun untuk kestabilan dan keakuratan deteksi system masih kurang. [2]

Selanjutanya pada paper Aplikasi Augmented Reality Gamelan Sebagai Media Pembelajaran Mengenal Gamelan Jawa Berbasis Augmented Reality pada Perangkat Mobile Android Dengan Studi Kasus : MI Ma'Arif 1 Pageraji. Pada penelitiannya penulis menggunakan metode marker based tracking diamana marker merupakat target image. Pada aplikasi tersebut selain menampilkan objek 3D berupa gamelan Jawa, tetapi juga dilengkapi dengan informasi berupa deskripsi dan bunyi irama pada masing-masing alat music gamelan tersebut. Sehingga dapat memberikan visualisasi kepada siswa bagaimana bentuk dan suara masing-masing dari gamelan Jawa tersebut. [3]

Endah Sudarmilah, Dkk dengan penelitiannya yang berjudul Augmented Reality Edugame Senjata Tradisional Indonesia telah berhasil memadupadankan teknologi terkini dengan system pembelajaran dan materi yang terbarukan. Pada game yang telah dibuat telah disisipkan materi pembelajaran mengenai senjata tradisional Indonesia. Sehigga selain dengan visualisasi game adventure yang menarik, tetaoi juga dapat menyajikan materi tentang keberagaman budaya yang dapat membuat siswa lebih bisa memahami materi pembelajaran khususnya senjata tradisional Indonesia. [4]

Pada penelian Geri Defandra, memanfaatkan metode marker based tracking untuk mebuat suatu aplikasi animasi 3D. Dengan papernya yang berjudul Aplikasi Animasi 3D Cerita Relief Jataka Berbasis Android Augmented Reality. Aplikasi tersebut memuat informasi mengenai beberapa relief yang ada pada candi Borobudur dengan tujuan sebagai sarana pembelajaran sejarah candi di Indonesi dalam bentuk animasi 3D. Seperti penelitian kebanyakan mengenai augmented reality menggunakan metode marker based tracking. Faktor cahaya dan jarak marker sangat menentukan keberhasilan dari penggunakan fitur scan marker pada aplikasi. [5]

Mifta Andriansyah pada penelitian pembuatan Aplikasi Warisan Budaya Senjata Tradisional Provinsi Banten Berbasis Augmented Reality pada Smartphone Android. Dengan menggunakan marker based tracking dan penelitian sendiri di fokuskan sebagai sarana pelestarian budaya senjata Banten. Selain objek dan marker, spesifikasi system ataupun hardware sangat berpengaruh agar aplikasi dapat berjalan dengan lancar. Untuk system disarankan minimal menggunakan OS v4.4 Kitkat, snapdragon 410, RAM 1 GB dan kamera 8MP agar marker dapat terdeteksi dengan baik. [6]

\subsection{Dasar Teori}

\subsubsection{Augmented Reality}

Augmented Reality (AR) adalah istilah untuk lingkungan yang menggabungkan dunia nyata dan dunia virtual yang dibuat oleh komputer sehingga batas antara keduanya menjadi sangat tipis. Dengan teknologi AR, lingkungan nyata di sekitar akan dapat berinteraksi dalam bentuk digital (virtual). Informasi tentang objek dan lingkungan sekitar dapat ditambahkan ke dalam sistem AR yang kemudian akan ditampilkan pada layar dunia nyata secara real-time seolah-olah informasi tersebut nyata. AR memiliki banyak potensi di dalam industri dan penelitian akademis.[7]

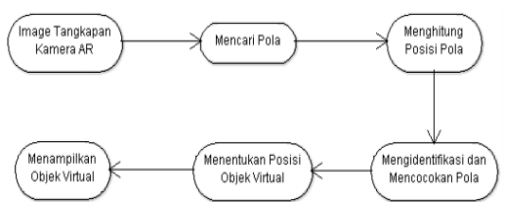

Gambar 2.1 Cara kerja augmented reality

Teknologi AR ini dapat menyisipkan suatu informasi tertentu ke dalam dunia maya dan menampilkannya di dunia nyata dengan bantuan perlengkapan seperti webcam, komputer, Smartphone, maupun kacamata khusus. Terdapat beberapa metode yang dapat digunakan dalam implementasi AR yaitu :

\section{Marker Based Tracking}

Marker biasanya merupakan ilustrasi hitam dan putih persegi dengan batas hitam tebal dan latar belakang putih. Komputer akan mengenali posisi dan orientasi marker dan menciptakan dunia virtual 3D yaitu titik $(0,0,0)$ dan tiga sumbu yaitu X, Y, dan Z. Marker Based Tracking ini sudah lama dikembangkan sejak 1980-an dan pada awal 1990-an mulai dikembangkan untuk penggunaan Augmented Reality. [8]

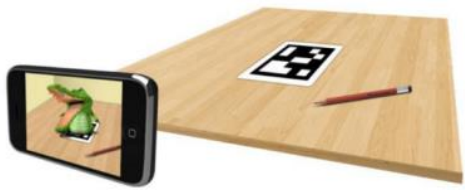

Gambar 2.2 Marker augmented reality

2. Markerless Augmented Reality

Markerless Augmented Reality, dengan metode ini pengguna tidak perlu lagi menggunakan sebuah marker untuk menampilkan elemen-elemen digital. Dengan 
tool yang disediakan Qualcomm untuk pengembangan Augmented Reality berbasis mobile device, mempermudah pengembang untuk membuat aplikasi dengan metode markerless (Qualcomm, 2012). Seperti yang saat ini dikembangkan oleh perusahaan Augmented Reality terbesar di dunia Total Immersion dan Qualcomm, mereka telah membuat berbagai macam teknik Markerless Tracking sebagai teknologi andalan mereka, seperti Face Tracking, 3D Object Tracking, dan Motion Tracking

\subsubsection{Vuforia}

Vuforia merupakan library Augmented Reality Software Development Kit (SDK) yang digunakan sebagai pendukung adanya augmented reality pada android. Vuforia menganalisa gambar dengan menggunakan pendeteksi marker dan menghasilkan informasi 3D dari marker yang sudah dideteksi. SDK ini menggunakan teknologi computer vision untuk mengenali dan melacak gambar planar (Gambar Target) dan objek 3D sederhana, seperti kotak, secara realtime. Kemampuan vuforia yang dapat merubah kertas dengan latar kosong menjadi tampilan dengan grafis 3D yang menarik, karena adanya teknologi augmented reality. Dengan vuforia, developer dapat memaksimalkan kemampuan teknologi augmented reality untuk menciptakan konten seperti, aplikasi, game, iklan dan presentasi. Vuforia menyediakan Antarmuka Application Programming (API) di C++, Java, Objective-C, dan bahasa Net.[9]

\subsubsection{Image Target}

Image Target adalah gambar yang bisa dilacak dan dideteksi oleh Vuforia SDK. Vuforia SDK mengaplikasikan algoritma khusus untuk mendeteksi dan melacak fitur yang secara natural ditemukan didalam sebuah gambar. Vuforia SDK mengenali image target dengan membandingkan fitur yang ada pada gambar fisik dengan gambar yang ada didalam database aplikasi. Ketika gambar terdeteksi, SDK akan melacak gambar selama berada di sudut pandang kamera. Fitur yang dilacak oleh Vuforia SDK adalah detail berbentuk sudut pada gambar. Gambar yang akan digunakan sebagai image target harus memiliki beberapa kriteria pembuatan image target yaitu:

a. Memiliki format 8 atau 16-bit dan JPG atau PNG.

b. Gambar berformat JPG harus memiliki warna RGB atau grayscale

c. Memiliki resolusi minimal 320 pixel.

d. Memiliki ukuran maksimal 2 MB.

e. Gambar tidak memiliki pola yang berulang.

Setelah diunggah, secara otomatis gambar akan mendapat implementasi algoritma yang dibuat khusus oleh vuforia sehingga fitur-fitur bisa terlihat dengan jelas. [10]

\subsubsection{Android}

Android adalah sebuah sistem operasi perangkat mobile berbasis linux yang mencakup sistem operasi, middleware dan aplikasi. Android menyediakan platform terbuka bagi para pengembang untuk menciptakan aplikasi mereka. Android merupakan generasi baru platform mobile yang memberikan kesempatan kepada pengembang untuk melakukan pengembangan sesuai dengan yang diharapkan. [11]

Sejak dirilisnya Android pada tahun 2008, Android kerap mengeluarkan versi terbarunya. Berikut adalah perkembangan versi Android hingga saat ini :

1. Android 1.0 (API level 1)

2. Android 1.1 (API level 2)

3. Android 1.5 Cupcake (API level 3)

4. Android 1.6 Donut (API level 4)

5. Android 2.0 Eclair (API level 5)

6. Android 2.2-2.2.3 Froyo (API level 8)

7. Android 2.3-2.3.2 Gingerbread (API level 9)

8. Android 2.3.3-2.3.7 Gingerbread (API level 10)

9. Android 3.0 Honeycomb (API level 11)

10. Android 3.2 Honeycomb (API level 13)

11. Android 4.0-4.0.2 Ice Cream Sandwich (API level 14)

12. Android 4.0.3-4.0.4 Ice Cream Sandwich (API level 15)

13. Android 4.1 Jelly Bean (API level 16)

14. Android 4.2 Jelly Bean (API level 17)

15. Android 4.3 Jelly Bean (API level 18)

16. Android 4.4 KitKat (API level 19)

17. Android 5.0 Lollipop (API level 21)

18. Android 6.0 Marshmallow (API level 23)

19. Android 7.0 Nougat (API 24)

20. Android 7.1 Nougat (API 25)

21. Android 8.0 "OREO" (API 26)

22. Android 9.0 Pie (API 27)

\subsubsection{Unity 3D 2018.3}

Unity adalah sebuah bentuk teknologi terbaru yang meringankan dan memudahkan game develop dalam membuat game. Selain untuk membuat game, unity 3D juga dapat digunakan untuk membuat konten yang interaktif lainya seperti, visual arsitektur dan real-time 3D animasi. [12] Co-founder dan CEO Unity tahun 2013, mengungkapkan bahwa Unity adalah seperangkat tools yang dapat digunakan untuk membangun game dengan berbagai teknologinya yang meilputi teknologi grafis, audio physics, interactions, dan networking. Berdasarkan beberapa uraian tersebut, maka dapat disimpulkan bahwa Unity merupakan software 
engine yang dapat digunakan untuk mengembangkan berbagai game multi-platform yang mudah digunakan.[13]

\subsubsection{Blender 2.80}

Blender merupakan OSS (Open Source SOftware) atau istilah lainnya software yang dapat di gunakan di berbagai macam OS (Operating System). Ini digunakan untuk dikembangkan secara komersial, tetapi sekarang dirilis di bawah GPL (GNU General Public License). Target di profesional media dan seniman, Blender dapat digunakan untuk membuat visualisasi $3 \mathrm{D}$, serta siaran dan video berkualitas bioskop, sedangkan penggabungan mesin 3D real-time memungkinkan penciptaan konten 3D interaktif untuk pemutaran yang berdiri sendiri. Blender memiliki berbagai macam kegunaan termasuk pemodelan, menjiwai, rendering, texturing, menguliti, rigging, pembobotan, editing nonlinear, scripting, composite, post-produksi dan banyak lagi.

\subsubsection{Senjata Tradisional}

Senjata merupakan suatu alat yang digunakan untuk melukasi, membunuh atau menghancurkan suatu benda. Senjata dapat digunakan untuk menyerang maupun untuk mempertahankan diri dan juga mengancam dan melindungi. Istilah tradisional berasal dari kata "tradisi" yang menunjuk kepada suatu lembaga, artefak, kebiasaan atau perilaku yang didasarkan pada tata aturan atau norma tertentu baik secara tertulis maupun tidak tertulis yang diwariskan secara turun temurun dari suatu generasi ke generasi berikutnya.

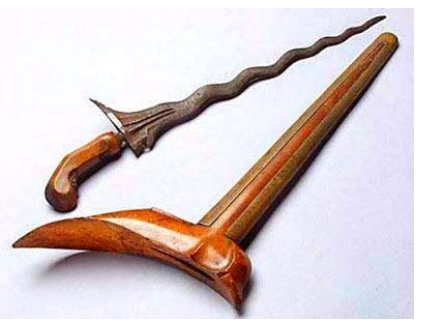

Gambar 2.3 Senjata tradisional keris

\subsubsection{FLowchart}

Flowchart adalah adalah suatu bagan dengan simbol-simbol tertentu yang menggambarkan urutan proses secara mendetail dan hubungan antara suatu proses (instruksi) dengan proses lainnya dalam suatu program. Flowchart adalah hasil dari suatu gambaran dalam menganalisa permasalahan dalam computer. Perancangan flowchart selalu terdiri dari tiga bagian yaitu input, proses dan output.

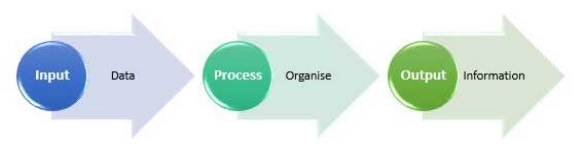

Gambar 2.4 Input process output

\section{METODE PENELITIAN}

3.1 Blok Diagram Sistem

Blok diagram adalah diagram dari sebuah sistem, di mana bagian utama atau fungsi yang diwakili oleh blok dihubungkan dengan garis, yang menunjukkan hubungan dari blok. Proses kerja pada aplikasi pengenalan senjata tradisional di tunjukkan pada gambar 3.1 berikut.

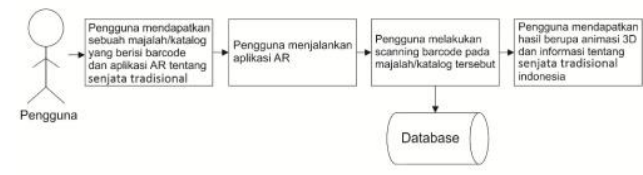

Gambar 3.1 Blok diagram sistem

Pada blok diagram system dapat diketahui langkah awal sebelum menjalankan aplikasi yaitu user mempunyai katalog yang berisi marker dan informasi mengenai aplikasi pengenalan senjata tradisional mengguanakan augmented reality berbasis Android. Kemudian user menjalankan aplikasi dan memilih Bahasa kemudian melakukan scan, dimana marker akan di scan kemudian system akan mengambil informasi berupa objek 3D dari database.

\subsection{Flowchart sistem}

Flowchart sistem ini menjelaskan proses berjalananya aplikasi seperti terlihat pada Gambar 3.2 berikut.

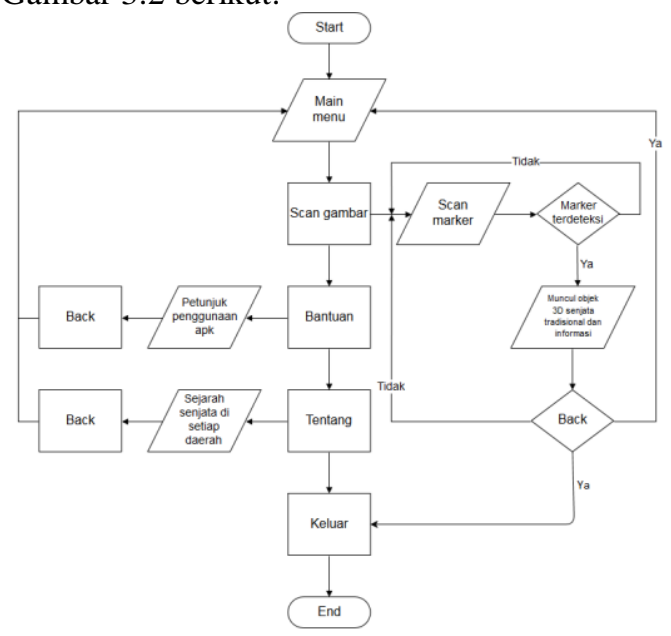

Gambar 3.2 Flowchart sistem

Pada flowchart sistem di atas proses dimulai dari start yaitu splash screen pada aplikasi. Kemudian masuk pada halaman pemilihan Bahasa. Selanjutnya adalah halaman 
scan marker yang langsung terhubung dengan kamera smartphone. Setelah kita lakukan scan marker dan jika marker sesuai maka akan muncul objek 3D dan informasi deskripsi berupa audio yang dapat di akses melalui button narasi. Selanjutnya terdapat fitur bantuan yang berisi cara penggunaan aplikasi. Terdapat fitur tentang yang berisi deskripsi aplikasi dan profil developer. Dan proses berakhir apabila kita menekan tombol keluar aplikasi atau end pada flowchart.

\subsection{Flowchart Augmented Reality}

Flowchart augmented reality ini menjelaskan proses pembacaan marker pada sistem augmented reality itu sendiri seperti pada Gambar 3.3 berikut.

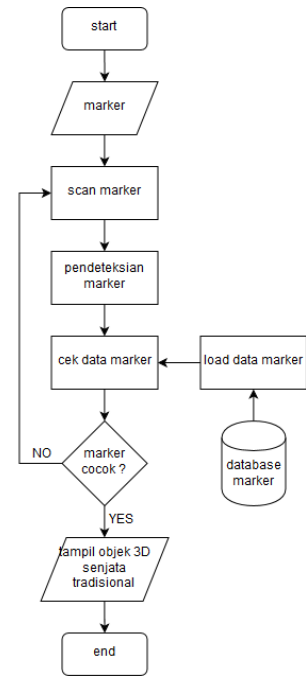

Gambar 3.3 Flowchart augmented reality

Proses pendeteksi marker di mulai dengan pembacaan marker oleh kamera smartphone. Kemudian kamera akan mendeteksi marker tersebut. Keakuratan deteksi pada marker bergantung pada beberapa hal, yaitu intensitas cahaya, jarak marker dengan kamera, dan resolusi kamera. Jika marker tidak terdeteksi, maka user harus mengatur marker dan menunjukkan kembali pada kamera. Jika marker terdeteksi maka akan muncul objek 3D dan informasi sesuai dengan marker.

\section{HASIL DAN PEMBAHASAN}

\subsection{Pengujian Tampilan Awal}

Tampilan awal pada aplikasi ini merupakan splash screen sebelum masuk ke tampilan menu utama. Berikut adalah tampilan dari spash screen seperti pada Gambar 4.1.

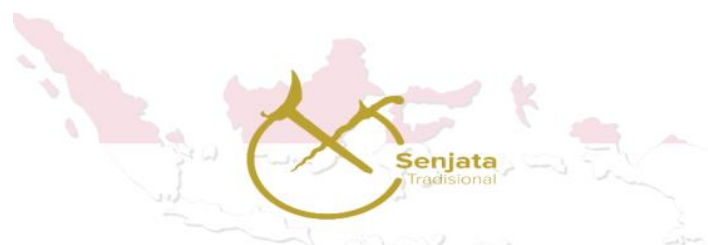

Gambar 4.1 Tampilan spash screen

\subsection{Pengujian Tampilan Pilih Bahasa}

Tampilan pilih bahasa pada aplikasi ini merupakan tampilan menu Bahasa yang akan digunakan. Pada tampilan pilih bahasa ini terdapat 2 button bahasa yaitu Indonesia dan Inggris seperti pada Gambar 4.2 berikut.

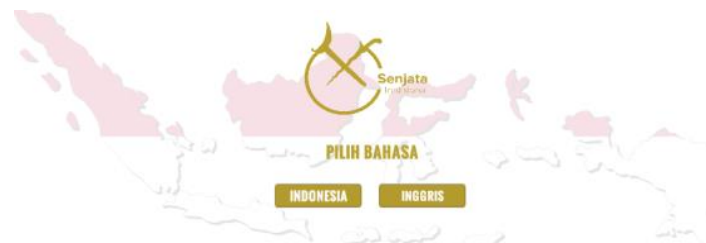

Gambar 4.2 Tampilan pilihan Bahasa

\subsection{Pengujian Tampilan Scan Marker}

Tampilan menu scan marker akan langsung tersambung dengan kamera smartphone. Pada tampilan menu mulai ini terdapat beberapa button yaitu informasi, bantuan, narasi dan keluar seperti pada Gambar 4.3 berikut.

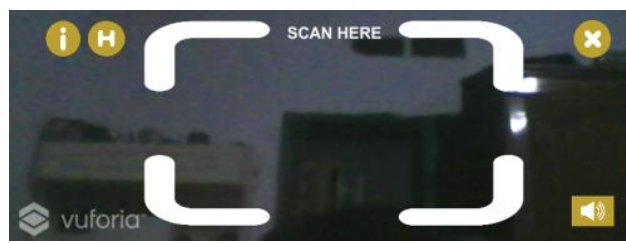

Gambar 4.3 Tampilan scan marker

Pada saat marker di hadapkan ke kamera aplikasi, aplikasi akan mendeteksi marker dan akan menampilan objek 3D, informasi, dan suara yang sebelumnya sudah teridentifikasi oleh aplikasi. Jika marker lain atau marker yang tidak terdaftar di dalam database aplikasi, maka aplikasi tidak akan menambilkan objek apapun. Adapun desain halaman tersebut seperti pada Gambar 4.4.

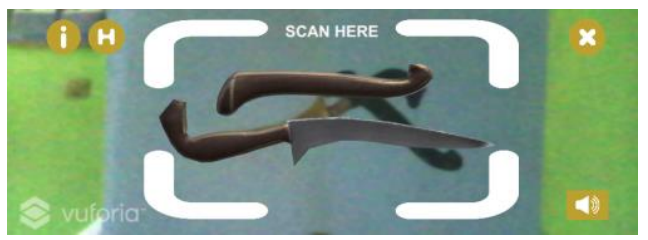

Gambar 4.4 Tampilan objek 3D senjata tradisional 


\subsection{Pengujian Tampilan Menu Informasi}

Tampilan menu informasi atau tentang ini berisi informasi mengenai aplikasi dan profil dari pengembang aplikasi dengan pilihan 2 bahasa Indonesia dan Inggris. Dilengkapi dengan button narasi yang berfungsi memberikan pejelasan menggunakan audio dan button kembali yang langsung mengarah pada menu scan marker seperti pada Gambar 4.5 berikut.

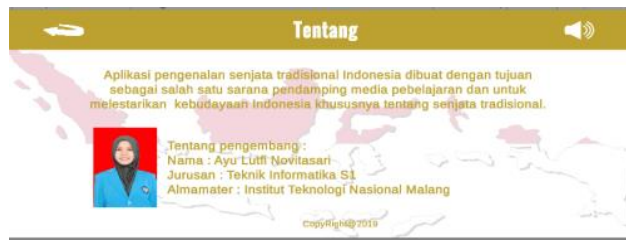

Gambar 4.5 Tampilan menu informasi

\subsection{Pengujian Tampilan Menu Bantuan}

Tampilan menu bantuan atau help ini berisi cara penggunaan aplikasi dengan pilihan 2 bahasa Indonesia dan Inggris. Dilengkapi dengan button narasi yang berfungsi memberikan pejelasan menggunakan audio dan button kembali yang langsung mengarah pada menu scan marker seperti pada Gambar 4.6 berikut.

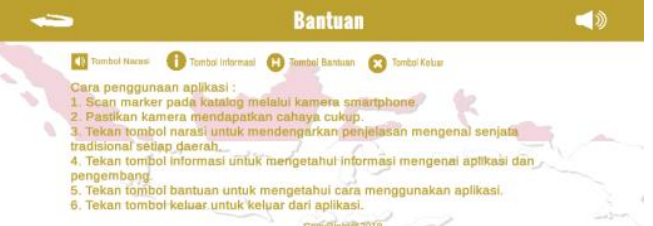

Gambar 4.6 Tampilan menu bantuan

\subsection{Pengujian Intensitas Cahaya}

Pengujian intensitas cahaya dilakukan pada dua waktu dan dua kondisi, yaitu siang dan malam, di dalam ruangan dan di luar ruangan. Untuk pengujian dapat di lihat pada Tabel 4.1.

\section{Tabel 4.1}

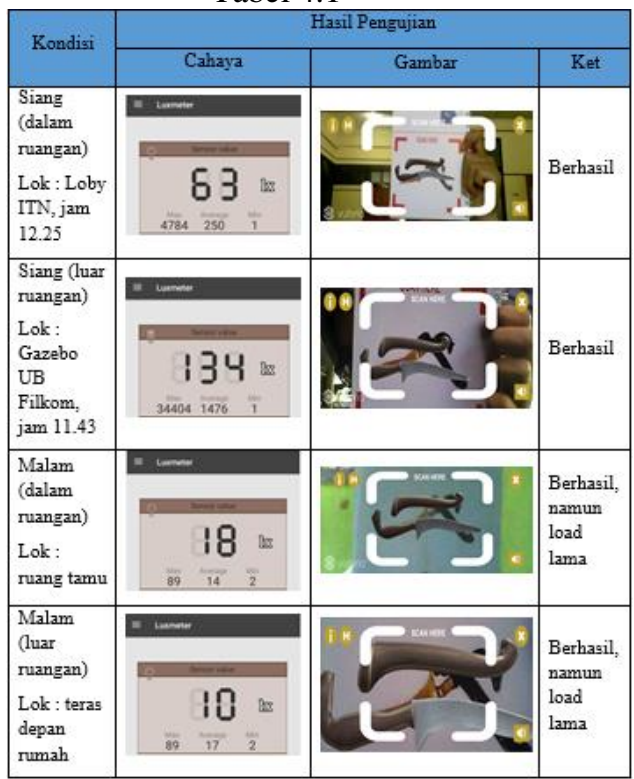

Dari hasil pengujain deteksi marker menggunakan intensitas cahaya didaptakan hasil semua marker dapat terdeteksi dengan rentang cahaya 10 lux sampai 134 lux. Semakin terang cahya semakin mudah untuk mendeteksi marker dan sebaliknya.

\subsection{Pengujian Deteksi Jarak}

Jarak merupakan faktor yang berpengaruh langsung terhadap proses deteksi marker. Semakin jauh jarak marker terhadap kamera, maka semakin kecil ukuran dan kualitas pola marker yang dapat di proses oleh aplikasi. Pengujian jarak ini bertujuan untuk mengetahui rentang jarak yang optimal agar marker dapat terdeteksi dengan baik. Pengujian di lakukan terhadap 3 rentangan jarak, yakni dekat $(10 \mathrm{~cm})$, sedang $(20 \mathrm{~cm})$, dan jauh $(30 \mathrm{~cm})$.

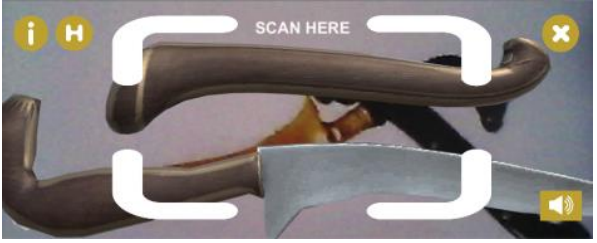

Gambar 4.7 Pengujian marker jarak $(10 \mathrm{~cm})$
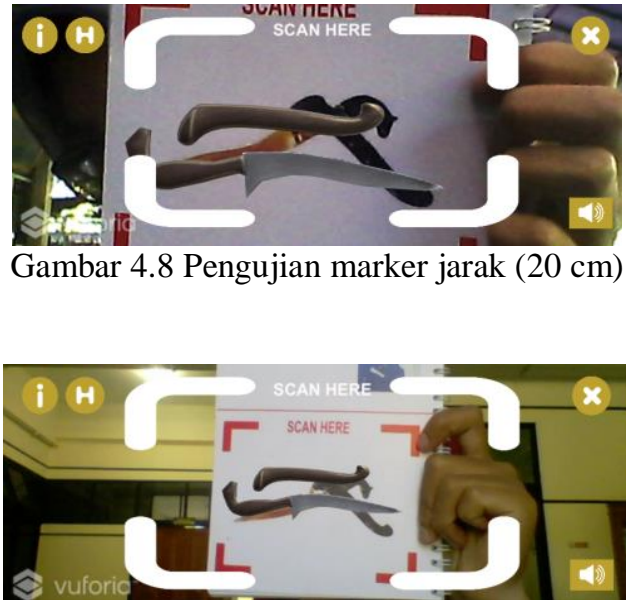

Gambar 4.9 Pengujian marker jarak $(30 \mathrm{~cm})$

Uji coba marker menggunakan 3 jarak yaitu jarak dekat $(10 \mathrm{~cm})$, jarak sedang $(20 \mathrm{~cm})$, dan jarak jauh (30). Dengan hasil semua marker dapat terdeteksi. Berdasarkan hasil uji coba jarak terhadap marker dapat diketahui jarak ideal agar marker dapat terdeteksi dengan baik adalah antara $10 \mathrm{~cm}$ sampai $20 \mathrm{~cm}$.

\section{KESIMPULAN DAN SARAN \\ 5.1 Kesimpulan}

Setelah dilakukanya pengujian pada aplikasi Pengenalan Senjata Tradisional Indonesia Menggunakan Augmented Reality berbasis Android, maka penulis mendapatkan kesimpulan sebagai berikut : 
1. Aplikasi menggunakan 2 bahasa yaitu Indonesia dan Inggris serta dilengkapi dengan audio narasi untuk mempermudah penyampaian informasi.

2. Marker berisi objek 3D 34 senjata tradisional dan informasi dalam bentuk audio.

3. Aplikasi dapat dijalankan menggunakan Android dengan minimum sistem operasi Marsmellow 5.0 dan RAM 1 GB.

4. Marker dapat terdeteksi dengan baik pada rentang jarak $10 \mathrm{~cm}$ sampai $20 \mathrm{~cm}$.

5. Marker dapat terdeteksi dengan intensitas cahaya antara 10 lux sampai 134 lux.

6. Kondisi yang baik untuk proses scan marker disarankan saat siang hari di dalam ruangan maupun di luar ruangan

\subsection{Saran}

Berdasarkan penelitian yang telah dilakukan maka penulis dapat memberikan saransaran untuk pengembangan selanjutnya karena penelitian ini masih terdapat banyak kekurangan, sehingga untuk penyempurnaan dapat ditambahkan :

1. Desain objek 3D yang lebih detail dan realistik serta tampilan UI agar semakin menarik bagi user.

2. Penambahan objek senjata tradisional apabila terdapat senjata baru.

3. Pengembangan dalam bentuk VR untuk menambah minat belajar dan pengetahuan mengenai kebudayaan Indonesia khususnya senjata tradisional.

\section{DAFTAR PUSTAKA}

[1] Pratama, Dera. Parno. 2014. E-LEARNING : BELAJAR KEBUDAYAAN NUSANTARA MENGGUNAKAN MULTIMEDIA. Depok.

[2] Danto, Walesa. DKK. 2011. Analisis Metode Occlusion Based Pada Augmented Reality Studi Kasus : Interaksi Dengan Objek Virtual Secara Real Time Menggunakan Gerakan Marker. Surabaya.

[3] Anshori, Fatah. 2014. APLIKASI "ARGAMELAN" SEBAGAI MEDIA PEMBELAJARAN MENGENAL GAMELAN JAWA BERBASIS AUGMENTED REALITY PADA
PERANGKAT MOBILE ANDROID (Studi Kasus: MI Ma'arif $\mathrm{Nu} 1$ Pageraji). Purwokerto.

[4] Sudarmillah, Endah. DKK. 2015. Augmented Reality Edugame Senjata Tradisional Indonesia. Surakarta.

[5] Defandra, Geri. 2017. APLIKASI ANIMASI 3D CERITA RELIEF JATAKA BERBASIS ANDROID AUGMENTED REALITY DENGAN METODE MARKER BASED TRACKING. Yogyakarta.

[6] Andriansyah, Miftah. DKK. 2018. APLIKASI WARISAN BUDAYA

SENJATA TRADISIONAL PROVINSI BANTEN BERBASIS AUGMENTED REALITY PADA SMARTPHONE ANDROID. Depok.

[7] Candra. 2014, Perancangan Sistem Interaksi Berbasis Teknologi Augmented Reality pada Sampul Media Promosi Cetak.

[8] Laxuardy, Senja. 2012. Augmented Reality : Masa Depan Interaktivitas, https://tekno.kompas.com/read/2012/04/09/ 12354384/Augmented.Reality.Masa.Depan. Interaktivitas. (Kamis, 23 May 20191.54 PM).

[9] Purnamawati. Eldrani. 2001. Media Pembelajaran CV. Rajawali. Jakarta.

[10] Rizky. K, Ramdhan. DKK. Aplikasi Media Pembelajaran Tulang Manusia Menggunakan Augmented Reality (AR) Berbasis Android. (Kamis, 23 May 2019 1.54 PM).

[11] Kurniawan, .K, 2011. Apa itu Android. Pengertian Android Secara Singakt. http;//thekaku.com/apa-itu-Androidpengertian-Android-secara-singkat. (Kamis, 23 May 2019 1.54 PM).

[12] Yulianto, Nanang .2012. Pembuatan Game 3 Dimensi Lost In Jungle dengan Menggunakan Unity 3D Game Engine. http://repository.amikom.ac.id/files/Publika si_10.21.0535. (Kamis, 23 May 20191.54 PM).

[13] Bunny, D. 2016. Sejarah dan pengertian dan kegunaan dari aplikasi blender. https://dsbunny.wordpress.com/2015/05/26/ sejarah-pengertiandan-kegunaan-dariaplikasi-blender-3d/. (Kamis, 23 May 2019 1.54 PM) 